\title{
Past ultraviolet radiation environments in lakes derived from fossil pigments
}

\section{Peter R. Leavitt ${ }^{\star}$, Rolf D. Vinebrooke*, David B. Donald $\dagger$, John P. Smol $¥$ \& David W. Schindler $\$}

* Limnology Laboratory, Department of Biology, University of Regina, Regina, Saskatchewan S4S 0A2, Canada

$\dagger$ Environment Canada, Ecosystems Division, Regina, Saskatchewan, S4P 4K1, Canada

$\ddagger$ Paleoecological Environmental Assessment and Research Laboratory, Department of Biology, Queen's University, Kingston, Ontario K7L 3N6, Canada $\S$ Department of Biological Sciences, University of Alberta, Edmonton, Alberta T6G 2E9, Canada

Natural levels of ultraviolet (UV) radiation can harm organisms in shallow aquatic ecosystems in which concentrations of photoprotective dissolved organic carbon are $l o w^{1-3}$. These compounds can be removed as a result of acidic precipitation and climate changes, an effect which may have recently been manifested in up to 200,000 boreal lakes ${ }^{4,5}$. Unfortunately, meteorological and biological monitoring studies are usually too brief to record the magnitudes of past changes in UV radiation fluxes and their effects. Here we demonstrate that certain fossil pigments in lake sediments can be used to document historical changes in the UV radiation environment of lakes. These pigments are produced by benthic algae when exposed to UV radiation and show sedimentary concentrations that are correlated to the depth of penetration of UV radiation within lakes. Analysis of fossil profiles from the sediments of two mountain lakes suggests that past UV radiation penetration has sometimes been-at least in these mid-latitude lakes-greater than during the period of anthropogenic stratospheric ozone depletion.

Analysis of sedimentary deposits in lakes has been used to document a wide variety of environmental perturbations, including climate warming, acidic precipitation and lake eutrophication ${ }^{6,7}$. We have proposed that fossil analyses might also record changes in past UV radiation environments because pigments from algae are often well-preserved in lake sediments ${ }^{8}$, and because some algae produce unique pigments on exposure to UV radiation ${ }^{9,10}$. Recently we have recorded the presence of UV-radiation-absorbing pigments in the sediments of alpine lakes ${ }^{11}$ where UV radiation was known to penetrate deeply ${ }^{12}$ and inhibit growth of benthic algae on artificial substrates $^{13}$. Mountain lakes may be particularly sensitive to UV radiation both because they are exposed to naturally high fluxes of it $^{14,15}$ and because they contain low concentrations of terrestrial dissolved organic carbon (DOC) ${ }^{16}$, the main attenuator of UV radiation in lakes ${ }^{17}$.

Surveys of clear lakes were conducted in 1994 and 1995 to establish the distribution of UV-radiation-absorbing sedimentary pigments among lakes of differing depth and DOC content. Lakes (62) in Banff, Jasper and Yoho National Parks in the Canadian Rocky Mountains $\left(51^{\circ} 00^{\prime}-53^{\circ} 30^{\prime} \mathrm{N}, 115^{\circ} 30^{\prime}-119^{\circ} 30^{\prime} \mathrm{W}\right)$ were chosen to span a wide range of limnological conditions ${ }^{18}$. Ekman grab samples were used to collect sufficient sediments from the deepest point in each lake. Flocs of recently deposited algae were recovered from the mud-water interface, indicating that sediments were relatively undisturbed. Surface sediments $(2-3 \mathrm{~cm}$ deep) were isolated from samples by hand-held mini-core sampler, frozen and analysed for pigments and organic matter content. Depthintegrated water samples were collected from the epilimnion of each lake in August 1995 and analysed for DOC content. Weekly samples over three summers in several alpine lakes revealed that mean DOC concentrations ( \pm standard error, s.e.) varied little between years $\left(0.68 \pm 0.05 \mathrm{mgl}^{-1}, n=3\right)$ or within years (s.e. $=0.10-0.16, \quad n=9-11)$ under current climate regimes (D.W.S., unpublished data).

Sedimentary pigments, including carotenoids, chlorophylls and derivatives from algae and bacteria, were used to estimate the

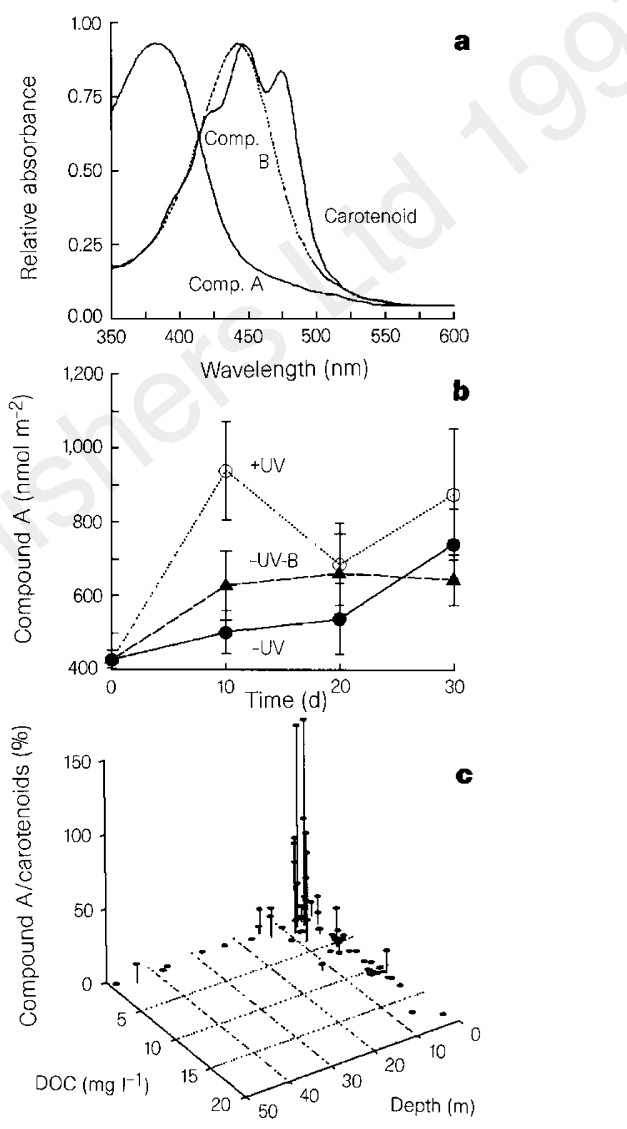

Figure 1 a-c, Absorbance spectra, production and distribution of ultravioletradiation-specific pigments isolated from mountain lakes. a, Relative absorbance of a carotenoid from green algae (lutein; absorption peaks of 472, 444.5, $420 \mathrm{~nm}$ ), compound $B\left(\lambda_{\max }=441 \mathrm{~nm}\right)$ and compound $A\left(\lambda_{\max }=381 \mathrm{~nm}\right)$ measured in acetone or $10 \%$ aqueous methanol using a Hewlett-Packard photo-diode array spectrophotometer. Both non-fluorescent compounds were isolated by HPLC, purified using a Sep-Pak C-18 cartridge, passed again through the chromatography column and isolated, dried under $\mathrm{N}_{2}$, and dissolved in HPLC-grade solvents before spectrophotometry. Spectra are similar to those of authentic scytonemin (supplied by F. Garcia-Pichel, Max Planck Institute for Marine Microbiology, Bremen). Retention times of compound A ( $6.1 \mathrm{~min}$ ) and compound B (5.7 min) were in the range of those of fucoxanthin from diatoms ( $5.0 \mathrm{~min}$ ), violaxanthin from higher plants (6.4 min) and the chromatographic dye Sudan II (7.3 min). b. Production of UV-radiation-specific pigment (compound A; mean \pm s.e., $n=6$ ) on mud substrates in Pipit Lake, Alberta, Canada, exposed to natural levels of UV radiation (+UV, screened with Acrylite OP4), no UV radiation (-UV; Plexiglas UF3), or UV-A radiation alone (-UV-B; Mylar D). UV radiation screens $(120 \times 60 \mathrm{~cm})$ were suspended $15 \mathrm{~cm}$ over an enclosed 50-cm water column for $30 \mathrm{~d}$. Pigments in the surface $5 \mathrm{~mm}$ of lake mud were sampled using standard gravity core procedures ${ }^{23}$. c. Abundance of compound A relative to the sum of indicator carotenoids (alloxanthin, lutein-zeaxanthin, diatoxanthin) as a function of average lake depth and summer DOC concentration. Relative abundance of compound A is greatest in lakes with low integral attenuation of UV radiation. Sedimentary compounds $\mathrm{A}$ and $\mathrm{B}$ were quantified assuming each had structural and lightextinction characteristics similar to those of carotenoid lutein. Fossil concentrations of compounds $A$ and $B$ were expressed relative to the sum of indicator algal pigments so that the $U V$ radiation index would vary as a function of $U V$ radiation or DOC, independent of algal abundance. 

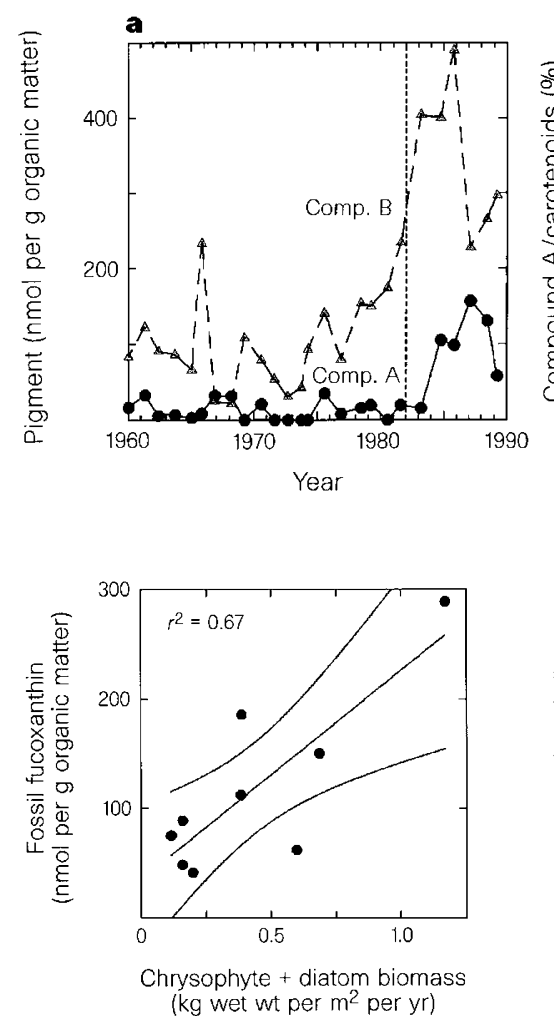
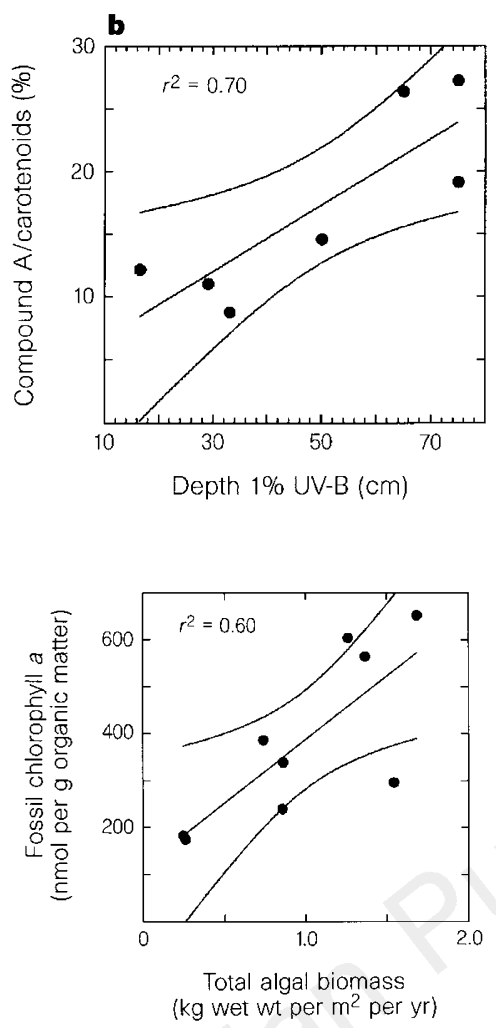

Figure 2 a, Concentration of fossil UV-radiation-specific pigments (compounds A and B) as a function of time in Lake 302.

These concentrations increased three- to ten-fold following lake acidification (1982-90), loss of DOC and increased penetration of UV radiation. $\mathbf{b}$, The relative abundance of compound $A$ was correlated $(P<0.05)$ to the mean depth of UV-B penetration between 1978 and 1987. UV-radiation-specific pigments were not detected in cores from three shallow reference lakes with surface blooms of algae, but low UV radiation transparency.

Figure 3 Concentrations of labile,19 fossil pigments (top, fucoxanthin; bottom, chlorophyll a) in Lake $302 S$ were correlated $(P<0.05)$ to the biomass of their respective algal populations between 1978 and 1990. Fucoxanthin is derived mainly from chrysophytes and diatoms ${ }^{8,29}$, whereas chlorophyll $a$ is ubiquitous among algae $e^{8}$. Phytoplankton were collected and quantified using consistent, standard techniques ${ }^{19,30}$. Linear correspondence between algal and fossil abundance demonstrates that stratigraphic patterns of even highly labile fossil pigments in Lake $302 S$ were not artefacts arising from post-depositional degradation, such as can occur in other lakes ${ }^{8,19}$. abundance and community composition of primary producers in each lake ${ }^{8,19}$. Pigments were extracted, isolated, identified and quantified using standard procedures, including high-performance liquid chromatography, HPLC ${ }^{20}$. Recent calibrations of fossil pigment concentrations against long-term historical records suggest that sedimentary pigments can be as reliable as morphological fossils from algae and can accurately record major changes in algal abundance and community composition ${ }^{19}$.

Sediments from many shallow lakes contained two unique nonfluorescent pigments that represent environments of high UV radiation flux (Fig. 1a). Compound A strongly absorbed UV radiation (wavelength of maximum absorbance $\lambda_{\max }=381 \mathrm{~nm}$ ), whereas carotenoid-like compound $\mathrm{B}$ had $\lambda_{\max }=441 \mathrm{~nm}$. These spectra are similar to the oxidized (compound A) and alkaline (compound B) forms of scytonemin, a pigment produced in the sheaths of certain cyanobacteria on exposure to UV radiation ${ }^{9,21}$. However, both sedimentary pigments were distinguishable from authentic scytonemin on our HPLC system ${ }^{20}$. We infer that compounds A and B are biological products of sediment-dwelling algae because intensive sampling in three alpine lakes ${ }^{11,13}$ revealed that the pigments were absent from the water column and rock substrates, yet were abundant in soft sediments. As well, experimental elimination of either UV-B $(280-320 \mathrm{~nm})$ or total UV radiation $(<$ $400 \mathrm{~nm}$ ) using differentially-absorbent aerial screens significantly reduced (repeated measures analysis of variance, $P<0.05$ ) production of both compound $\mathrm{A}$ and $\mathrm{B}$ on the bottom of alpine Pipit Lake ${ }^{11,13}$ relative to mud that received natural irradiances, consistent with the photo-protective function of these pigments (Fig. 1b). Further characterization of compounds A and B are underway.

Pigments specific to the presence of UV radiation were most abundant in shallow lakes (mean depth $<5 \mathrm{~m}$ ) with low concentrations of UV-radiation-absorbing DOC $\left(<2 \mathrm{mgl}^{-1}\right.$; Fig. 1c). In general, relative abundance of compound A was greatest in alpine lakes, the sites with the highest ambient UV radiation ${ }^{14,15}$ and lowest mean concentrations of DOC $\left(0.9 \pm 0.7 \mathrm{mgl}^{-1} ; n=25\right)$. Because compounds A and B were only abundant in lakes with low integral attenuation of UV radiation, we suggest that high relative abundance of these compounds may be a useful marker of an increased depth of penetration of UV radiation in lakes. We tested this hypothesis by analysing historical changes in compounds A and $\mathrm{B}$ in a temperate lake known to have undergone an eight-fold increase in penetration by UV radiation following experimental acidification ${ }^{4}$.

Experimental acidification of boreal Lake $302 \mathrm{~S}\left(49^{\circ} 02^{\prime} \mathrm{N}\right.$, $93^{\circ} 42^{\prime} \mathrm{W}$ ) with sulphuric acid reduced lakewater $\mathrm{pH}$ from 6.6 to 4.5 , reduced DOC from $\sim 7$ to $\sim 1.5 \mathrm{mgl}^{-1}$, and increased the maximum depth of UV-B penetration eight-fold between 1982 and $1990^{4}$. We used high-resolution freeze-coring techniques ${ }^{19}$ to collect undisturbed sediment cores from the deepest portion of Lake $302 \mathrm{~S}$ and three local reference lakes in January 1991. Sediments were sectioned in 3-mm intervals and analysed for pigment content using standard procedures ${ }^{19}$. Sediment age was estimated using accumulation rates from earlier ${ }^{210} \mathrm{~Pb}$-dated cores ${ }^{19,22}$ and, for Lake $302 \mathrm{~S}$, from changes in the fossil community composition of scaled chrysophyte algae, reliable indicators of lakewater $\mathrm{pH}^{23}$. Fossil chrysophyte community composition changed from Mallomonas duerrschmidtiae to acidophilic Synura echinulata dominance, concomitant with documented acidification in 1982. Inferences of $\mathrm{pH}$ change derived from chrysophytes ${ }^{23}$ were highly correlated $\left(r^{2}=0.85, P<0.001\right)$ with measured $\mathrm{pH}$, demonstrating that the fossil chronology in Lake $302 \mathrm{~S}$ was reliable.

Concentrations of fossil compounds A and B increased three- to ten-fold following the addition of acid to Lake 302S (Fig. 2a). These pigments were not recorded either in sediments from less acidic Lake $302 \mathrm{~N}$ (3.7-5.0 mg DOCl $\left.{ }^{-1} ; 1989-90\right)$, or in nearby unacidified lakes ${ }^{19}$. In particular, compounds $\mathrm{A}$ and $\mathrm{B}$ were absent from shallow reference lakes 227 and 226, eutrophic sites with extensive cyanobacteria populations $^{19}$ but high DOC content $\left(\sim 6 \mathrm{mgl}^{-1}\right)$, suggesting that surface blooms of algae do not produce signals of high transparency to UV radiation.

When expressed as a fraction of indicator carotenoid abundance, 


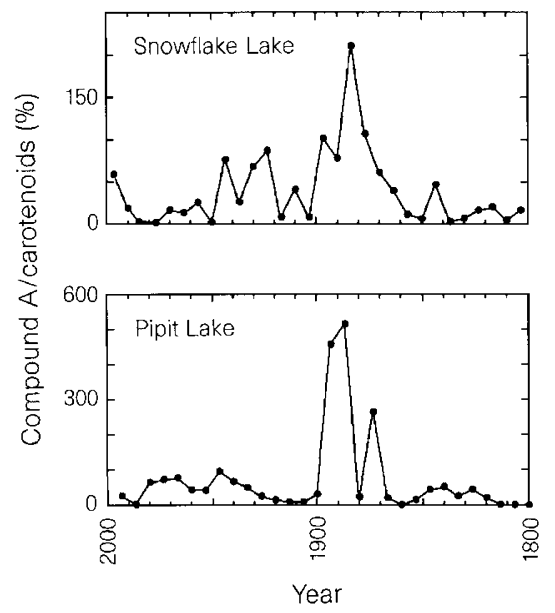

Figure 4 Regional increases in penetration of UV radiation in Snowflake Lake (top) and Pipit Lake (bottom) following droughts in western Canada ${ }^{25,26}$, indicated by elevated concentration of UV-radiation-specific pigment (compound A) from $\sim 1850$ to $\sim 1900$. Fossil compound A data are from ref. 11.

concentrations of UV-radiation-absorbing compound A were significantly correlated $(P<0.05)$ with the maximum depth of UV radiation penetration between 1978 and 1987 (Fig. 2b). Although the relationship was less reliable in the uppermost surface sediments $(6 \mathrm{~mm} ; 1988-90)$, these surficial deposits are frequently difficult to interpret because processes that form the fossil record are incomplete ${ }^{8}$. Overall stratigraphic patterns are unlikely to have resulted from post-depositional pigment degradation both because the deep-water oxygen content, and hence preservation environment ${ }^{8,19}$, has varied little in Lake 302 from 1972 to $1990^{4,24}$, and because concentrations of even labile, ${ }^{8,19}$ fossil pigments were linearly correlated $\left(r^{2}=0.60-0.67, P<0.05\right)$ with the abundance of their respective producer populations (Fig. 3). Relative abundances of compounds A and B were lower in Lake 3025 than in the most transparent alpine lakes, consistent with greater atmospheric attenuation of UV radiation at low elevations ${ }^{14,15}$, the relatively great mean depth of Lake $302 \mathrm{~S}(>5 \mathrm{~m})$, and residual reservoirs of UVradiation-absorbing DOC $\left(>1.4 \mathrm{mgl}^{-1}\right)$.

Pigments specific to the presence of UV radiation also recorded regional variations in UV penetration that may periodically harm aquatic organisms in undisturbed lakes (Fig. 4). For example, reanalysis of previously studied cores ${ }^{11}$ demonstrates that the relative abundance of compounds A and B increased sharply from $\sim 1850$ to 1900 in both Snowflake and Pipit lakes $\left(51^{\circ} 36^{\prime} \mathrm{N}\right.$, $115^{\circ} 50^{\prime} \mathrm{W}$ ), two similar alpine lakes located within $5 \mathrm{~km}$ of each other within Banff National Park, Canada ${ }^{11}$. Peak abundances of compounds $\mathrm{A}$ and $\mathrm{B}$ were greater than those exhibited by many present-day mountain lakes (Fig. 1c). This episode of greatly increased penetration of UV radiation occurred at the same time as droughts at low elevations ${ }^{25}$ and cool temperatures at the tree line in western Alberta ${ }^{26}$, as inferred from tree-ring analyses. Recent studies of poorly-buffered Precambrian Shield lakes have demonstrated that brief droughts can increase penetration of UV radiation by reducing concentrations of UV-radiation-absorbent $\mathrm{DOC}^{5,27,28}$. Our results suggest that droughts may affect a much wider range of lakes than previously supposed, including undisturbed, well buffered ${ }^{11}$ mountain sites and other locations with naturally low concentrations of DOC. Biological damage may be particularly severe in alpine lakes because they receive (and contain) less photo-protective terrestrial DOC $\left(0.9 \pm 0.7 \mathrm{mgl}^{-1} ; n=25\right)$ than do subalpine sites $\left(4.7 \pm 4.4 \mathrm{mg}^{-1} ; n=37\right)$.

More than 100,000 North American boreal lakes ${ }^{4}$ and many mountain lakes (Fig. 1) have such low concentrations of DOC $\left(\leqslant 2 \mathrm{mg} \mathrm{DOCl}^{-1}\right)$ that even slight reductions in DOC following droughts ${ }^{4,5,27,28}$ or acidification ${ }^{4,5}$ can vastly increase penetration of UV radiation. Because this penetration increases as a negative exponential function of DOC concentration ${ }^{4,12,17}$, drought-induced increases in UV radiation can exceed those anticipated from stratospheric ozone depletion ${ }^{4}$. Analysis of pigments in lake sediments provides a new tool to quantify the magnitude and regional extent of changes in UV-radiation penetration, particularly for lakes which lack historical data on UV radiation.

Received 9 September 1996; accepted 20 June 1997

1. Bothwell, M. L., Sherbot, D. \& Pollock, C. M. Ecosystem response to solar ultraviolet-B radiation: Influence of trophic-level interactions. Science 265, 97-100 (1994).

2. Karentz, D. et al. Impact of UV-B radiation on pelagic freshwater ecosystems: Report of working group on bacteria and phytoplankton. Arch. Hydrobiol. 43, 31-69 (1994).

3. Siebeck, O. et al. Impact of UV-B radiation on zooplankton and fish in pelagic freshwater ecosystems. Arch. Hydrobiol. 43, 101-114 (1994).

4. Schindler, D. W., Curtis, J. P., Parker, B. R. \& Stainton, M. P. Consequences of climate warming and lake acidification for UV-B penetration in North American boreal lakes. Nature 379, 705-708 (1996).

5. Yan, N. D., Keller, W., Scully, N. M., Lean, D. R. S. \& Dillon, P. Increased UV-B penetration in a lake owing to drought-induced acidification. Nature 381, 141-143 (1996).

6. Fritz, S. C., Juggins, S., Battarbee, R. W. \& Engstrom, D. R. Reconstruction of past changes in salinity and climate using a diatom-based transfer function. Nature 352, 706-708 (1991).

7. Douglas, M. S. V., Smol, J. P. \& Blake, W. Jr Marked post-18th century environmental change in high Arctic ecosystems. Science 266, 416-419 (1994).

8. Leavitt, P. R. A review of factors that regulate carotenoid and chlorophyll deposition and fossil pigment abundance. J. Paleolimnol. 9, 109-127 (1993).

9. Garcia-Pichel, F. \& Castenholtz, R. W. Characterization and biological implications of scytonemin, a cyanobacterial sheath pigment. J. Phycol. 27, 395-409 (1991).

10. Karentz, D., McEuen, F. S., Land, M. C. \& Dunlap, W. C. Survey of mycosporine-like amino acid compounds in Antarctic marine organisms: Potential protection from ultraviolet exposure. Mar. Biol. 108, 157-166 (1991).

11. Leavitt, P. R., Schindler, D. E., Paul, A. J., Hardie, A. K. \& Schindler, D. W. Fossil pigment records of phytoplankton in trout-stocked alpine lakes. Can. J. Fish. Aquat. Sci. 51, 2411-2423 (1994).

12. Scully, N. M. \& Lean, D. R. S. The attenuation of ultraviolet radiation in temperate lakes. Arch. Hydrobiol. 43, 135-144 (1994).

13. Vinebrooke, R. D. \& Leavitt, P. R. Effects of ultraviolet radiation on periphyton in an alpine lake. Limnol. Oceanogr. 41, 1035-1040 (1996).

14. Blumthaler, M. \& Ambach, W. Indication of increasing solar ultraviolet-B radiation flux in alpine regions. Science 248, 206-208 (1990).

15. Caldwell, M. M., Robberecht, R. \& Billings, W. D. A steep latitudinal gradient of solar ultraviolet-B radiation in the arctic-alpine life zone. Ecology 61, 600-611 (1980).

16. Baron, J., McKnight, D. \& Denning, A. S. Sources of dissolved and particulate organic material in Loch Vale watershed, Rocky Mountain National Park, Colorado, USA. Biogeochemistry 15, 89-110 (1991).

17. Morris, D. P. et al. The attenuation of solar UV radiation in lakes and the role of dissolved organic carbon. Limnol. Oceanogr. 40, 1381-1391 (1995).

18. Anderson, R. S. Crustacian plankton communities of 340 lakes and ponds in and near the national parks of the Canadian Rocky Mountains. J. Fish. Res. Board Can. 31, 855-869 (1974).

19. Leavitt, P. R. \& Findlay, D. L. Comparison of fossil pigments with 20 years of phytoplankton data from eutrophic Lake 227, Experimental Lakes Area, Ontario. Can. J. Fish. Aquat. Sci. 51, 2286-2299 (1994).

20. Mantoura, R. F. C. \& Llewellyn, C. A. The rapid determination of algal chlorophyll and carotenoid pigments and their breakdown products in natural waters by reverse phase high-performance liquid chromatography. Anal. Chim. Acta 151, 297-314 (1983).

21. Proteau, P. J., Gerwick, W. H., Garcia-Pichel, F. \& Castenholtz, R. W. The structure of scytonemin, an ultraviolet sunscreen pigment from the sheaths of cyanobacteria. Experimentia 49, 825-829 (1993).

22. Anderson, R. F., Schiff, S. L. \& Hesslein, R. H. Determining sediment accumulation and mixing rates using ${ }^{210} \mathrm{~Pb}$, ${ }^{137} \mathrm{Cs}$, and other tracers: Problems due to postdepositional mobility or coring artifacts. Can. J. Fish. Aquat. Sci. (suppl. 1) 44, 231-250 (1987).

23. Dixit, S. S., Dixit, A. S. \& Smol, J. P. Lake acidification recovery can be monitored using chrysophycean microfossils. Can. J. Fish. Aquat. Sci. 46, 1309-1312 (1989).

24. Schindler, D. W., Ruszczynski, T. \& Fee, E. J. Hypolimnetic injection of nutrient effluents as a method for reducing eutrophication. Can. J. Fish. Aquat. Sci. 37, 320-327 (1980).

25. Case, R. A. \& MacDonald, G. M. A dendroclimatic reconstruction of annual precipitation on the western Canadian prairies since A.D. 1505 from Pinus flexilis James. Quat. Res. 44, 267-275 (1995).

26. Luckman, B. H. Mountain areas and global change: A view from the Canadian Rockies. Mount. Res. Dev. 10, 183-195 (1990).

27. Schindler, D. W. et al. Climate-induced changes in the dissolved organic carbon budgets of boreal lakes. Biogeochemistry 36, 9-28 (1997).

28. Schindler, D. W. et al. The effects of climatic warming on the properties of boreal lakes and streams at the Experimental Lakes Area, northwestern Ontario. Limnol. Oceanogr. 41, 1004-1017 (1996).

29. Goodwin, T. W. The Biochemistry of the Carotenoids Vol. 1 Plants (Chapman \& Hall, London, 1980).

30. Findlay, D. L. \& Kasian, S. E. M. Phytoplankton communities of lakes experimentally acidified with sulfuric and nitric acids. Can. J. Fish. Aquat. Sci. 47, 1378-1386 (1990).

Acknowledgements. This work was supported by the Natural Sciences and Engineering Research Council of Canada.

Correspondence should be addressed to P.L. (e-mail: Leavitt@leroy.cc.uregina.ca) 